\title{
High Performance Recycling of Polymers by Means of Their Fluorescence Lifetimes*
}

\author{
Heinz Langhals\#, Dominik Zgela, Thorben Schlücker \\ Department of Chemistry, LMU University of Munich, Munich, Germany \\ Email: "Langhals@Irz.uni-muenchen.de
}

Received 6 June 2014; revised 5 July 2014; accepted 5 August 2014

Copyright (C) 2014 by authors and Scientific Research Publishing Inc.

This work is licensed under the Creative Commons Attribution International License (CC BY). http://creativecommons.org/licenses/by/4.0/

c) (i) Open Access

\section{Abstract}

Technical polymers could be identified by means of their remarkably strong auto fluorescence. The time constants of this fluorescence proved to be characteristic for the individual polymers and can be economically determined by integrating procedures. The thus obtained unequivocal identification is presented for their sorting for recycling. Furthermore, polymeric materials were doped with fluorescent dyes allowing a fine-classification of special batches.

\section{Keywords}

\section{Recycling, Polymers, Fluorescence Lifetime, Labelling, Fluorescence Spectroscopy}

\section{Introduction}

The recycling of organic polymers obtains an increasing interest both in research and technology. There is a necessity for the development of efficient processes because of increasing environmental pollution by polymers (“plastic planet”). Moreover, their recycling may open an economic source for organic materials. The majority of technical polymers are thermoplasts and melt and moulding again is attractive for their easy re-use. However, the immiscibility and incompatibility of organic polymers are therefore the main obstacles because lacking uniformity as low as 5\% lowers the value of polymers appreciably and an even higher uniformity is required for high performance materials. Pure polymers for recycling may be collected in polymer-processing manufactories, however, the majority of collected material forms mixtures where an efficient sorting is required before processing. The machine-based recognition of polymers is a prerequisite for such processes where methods using the density or electrostatic properties were described [1]-[3]. Optical methods are more attractive because of simple, stable and efficient technology where fluorescence is advantageous [4]-[8] because of unproblematic

*Dedicated to Prof. Ch. Rüchardt on the Occasion of His 85th Birthday.

\#Corresponding author. 
light path and detection. The doping of polymers with fluorescent markers [9] and their re-identification by the spectral resolution of their fluorescence in combination with a binary coding was described in preceding papers [10] [11]. This demonstrated the efficiency of the application of fluorescence. However, there are two topics for a fundamental improvement: 1) Only doped material can be recycled where the recycling has to be already targeted in the production of final products; undefined wastes cannot be recycled in this way; 2) the spectral resolution for every flake for recycling costs appreciable efforts for detection and signal processing. Optical processes for the sorting of undoped material would bring about an appreciable progress and would even allow working up deposited material.

\section{Experimental}

\subsection{Spectroscopy}

UV/Vis absorption spectra: Varian Cary 5000; fluorescence spectra: Varian Cary Eclipse; fluorescence lifetimes: Edinburgh Analytical Instruments CD900, nF900.

\subsection{Materials}

The technical polymers Luran $^{\circledR}$ (styrene, polyacrylonitile copolymer from BASF), Delrin ${ }^{\circledR}$ (polyoxymethylene from DuPont) and Ultramid ${ }^{\circledR}$ (polyamide with glass fibre from BASF) were applied without further treatment. The fluorescence labels 1 (PTIE) [15], 2 (S-13) [16], and 3 (S-13TBI) [17] [18] were prepared according to the literature. Spectroscopic grade solvents were applied.

\section{Results and Discussion}

\subsection{Auto Fluorescence of Polymers}

The identification of polymers was concentrated to the technical high performance products Luran ${ }^{\circledR}$, Delrin ${ }^{\circledR}$ and Ultramid $^{\circledR}$. We found an appreciable strong auto fluorescence of these technical materials with standard optical exciting at $365 \mathrm{~nm}$ where mercury lamps may be applied as a light source; see Figure 1. Slight variations of the wavelengths of excitation do not alter the spectra.

The investigated polymers exhibit individual shapes of their auto fluorescence spectra; see Figure 1 . We preferred a fluorescence excitation at $365 \mathrm{~nm}$ where intense light sources are available. A slight variation of the wavelength of excitation does not influence the fluorescence. The spectra may be used for the identification and sorting of polymers by means of methods of pattern search. Thus, even undoped material can be sorted, however, this requires still an appreciable effort of calculation.

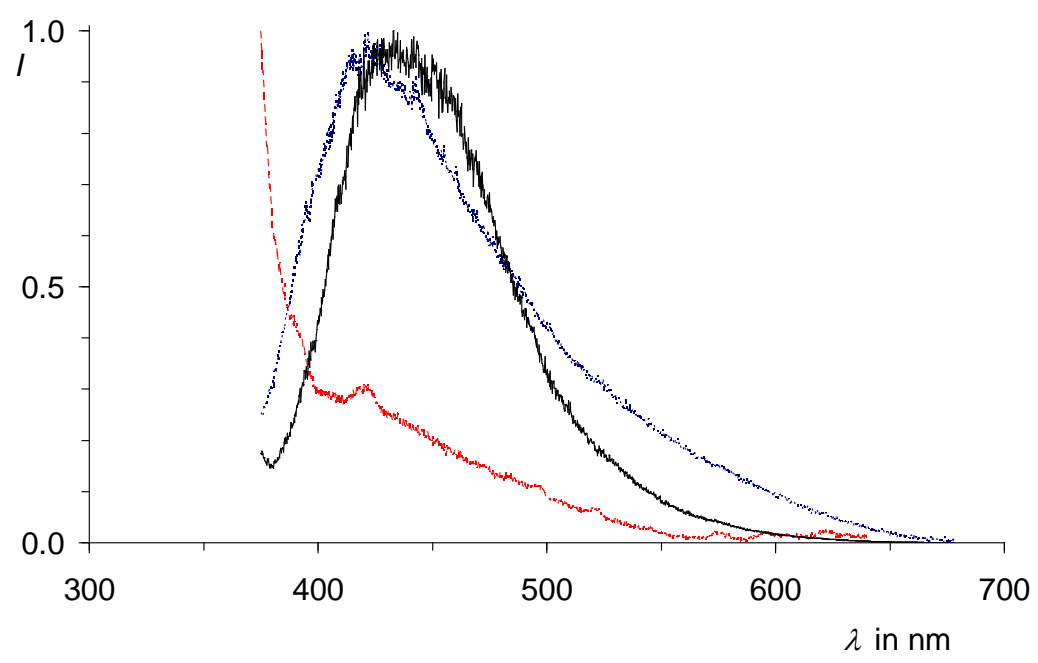

Figure 1. Fluorescence spectra of the auto fluorescence of Luran ${ }^{\circledR}$ (blue, dotted curve), Delrin ${ }^{\circledR}$ (red, dashed curve) and Ultramid ${ }^{\circledR}$ (black, solid curve) with optical excitation at $365 \mathrm{~nm}$. 
As an alternative, we investigated the fluorescence lifetimes of the auto fluorescence and found remarkable differences for various polymers; see Table 1 , lines 1 to 3 . Fluorescence decay essentially proceeds first order in time with the time constant $\tau$. Minor, less important bi-exponential components $\left(\tau_{\mathrm{bi}}\right)$ could be detected, however, a mono-exponential interpretation is sufficient for the identification by far. The decay curves can be easily splitted into two branches representing each of the single components of the fluorescence lifetime. Factors about two are between the decay times $\tau$ for Delrin ${ }^{\circledR}$, Ultramid ${ }^{\circledR}$ and Luran ${ }^{\circledR}$ allowing an unambiguous identification of the polymers.

The decay curves of the auto fluorescence of the polymers are reported in Figures 2(a)-(c) and are clearly indicating their pronounced differences. These can be even more easily seen in the fitted function in Figure 2(d). A simple logarithmic representation of the right branch of the decay curves is by far sufficient for the determination of the differences in lifetimes; right scales in Figure 2.

\subsection{Fluorescent Labels}

An additional labelling of the polymers by means of fluorescent dyes was taken into account for not only identifying the basic polymeric material but also special technological batches. We applied the perylene ester $\mathbf{1}$ (PTIE), the perylene carboxylic bisimide $\mathbf{2}$ (S-13) and the terrylene carboxylic bisimide $\mathbf{3}$ (S-13TBI) because of their light fastness and high fluorescence quantum yields. The fluorescence of these dyes proceeds in different spectral regions forming three channels for detection as can be seen from their fluorescence spectra in Figure 3. The spectra in various polymeric materials differ only slightly from the spectra in solution because solvatochromism of the dyes is weak. As a consequence, the three channels of fluorescence can be taken to be invariant with respect to the tested material. The labelling of polymers can proceed with a binary coding where the first or the second dye or both were applied and so on resulting in $2^{n}-1$ possibilities for labelling with $n$ as the number of applied fluorescent dyes: Thus, seven individual batches may be labelled for each polymeric material with the application on dyes 1 to 3 . The fluorescence spectra may be applied for the identification of the labelling with the individual dyes. The formation of the second derivative of the spectra improves [10] [11] the security of detection.

Furthermore, we found that the time constants for fluorescence decay vary both with the applied dye and the applied polymer; see Table 1 . Such combinations can be taken as an additional pattern for the recognition of the

Table 1. Fluorescence lifetimes of genuine polymers, the fluorescence labels in chloroform solution and doped polymers.

\begin{tabular}{|c|c|c|c|c|}
\hline Sample & $\tau$ in $\mathrm{ns}^{\mathrm{a})}$ & $\tau$ in $\mathrm{ns}^{\mathrm{b})}$ & $\lambda \mathrm{ex}^{\mathrm{c})}$ & $\lambda \mathrm{em}^{\mathrm{d})}$ \\
\hline Delrin & 0.74 & 5.78 & 365 & 573 \\
\hline Luran & 3.53 & 8.42 & 365 & 573 \\
\hline Ultramid & 1.96 & 7.83 & 365 & 573 \\
\hline PTIE (1) in $\mathrm{CHCl}_{3}$ & 3.53 & & 442 & 485 \\
\hline $\mathrm{S}-13(2)$ in $\mathrm{CHCl}_{3}$ & 4.06 & & 490 & 573 \\
\hline $\mathrm{S}-13 \mathrm{TBI} 3$ in $\mathrm{CHCl}_{3}$ & 3.66 & & 598 & 667 \\
\hline Delrin with PTIE (1) & 3.90 & & 442 & 485 \\
\hline Delrin with PTIE (1) & 3.92 & & 490 & 573 \\
\hline Delrin with S-13 (2) & 3.74 & & 490 & 573 \\
\hline Delrin with S-13TBI (3) & 3.31 & & 598 & 667 \\
\hline Delrin with S-13TBI (3) & 3.34 & & 490 & 667 \\
\hline Luran with PTIE (1) & 4.08 & & 490 & 573 \\
\hline Luran with S-13 (2) & 4.56 & & 490 & 573 \\
\hline Luran with S-13TBI (3) & 3.53 & & 598 & 667 \\
\hline Luran with S-13TBI (3) & 3.96 & & 490 & 667 \\
\hline Ultramid with PTIE (1) & 2.44 & 7.53 & 442 & 485 \\
\hline Ultramid with PTIE (1) & 2.26 & 5.75 & 490 & 573 \\
\hline Ultramid with S-13 (2) & 1.83 & 5.37 & 490 & 573 \\
\hline Ultramid with S-13TBI (3) & 2.34 & 6.98 & 598 & 667 \\
\hline
\end{tabular}

${ }^{\text {a) }}$ Fluorescence lifetime; ${ }^{\text {b) }}$ Additional biexponential component; ${ }^{\mathrm{c}}$ Wavelength of excitation in $\mathrm{nm}$; ${ }^{\mathrm{d})}$ Wavelength of detection in $\mathrm{nm}$. 

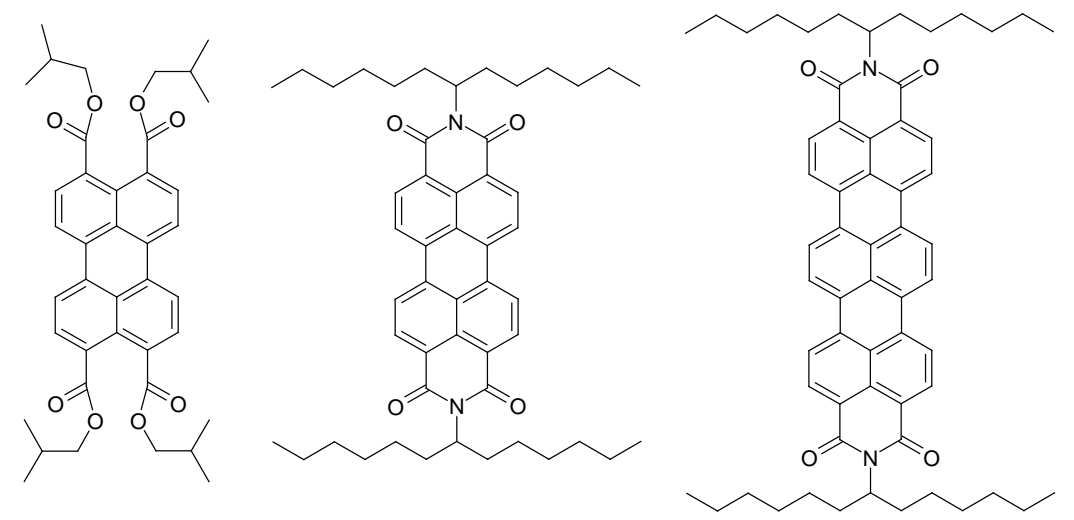

1

2

3

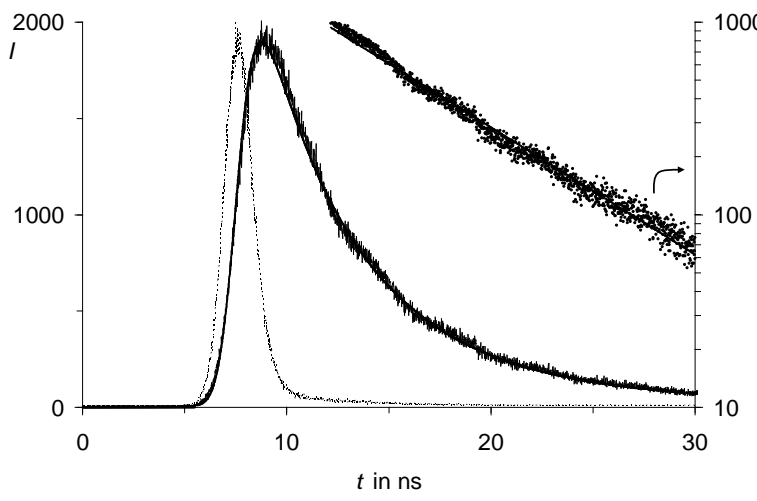

(a)

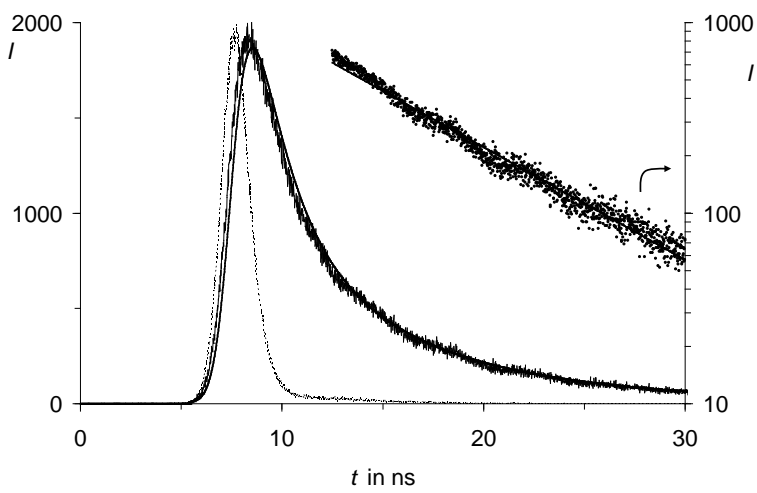

(c)

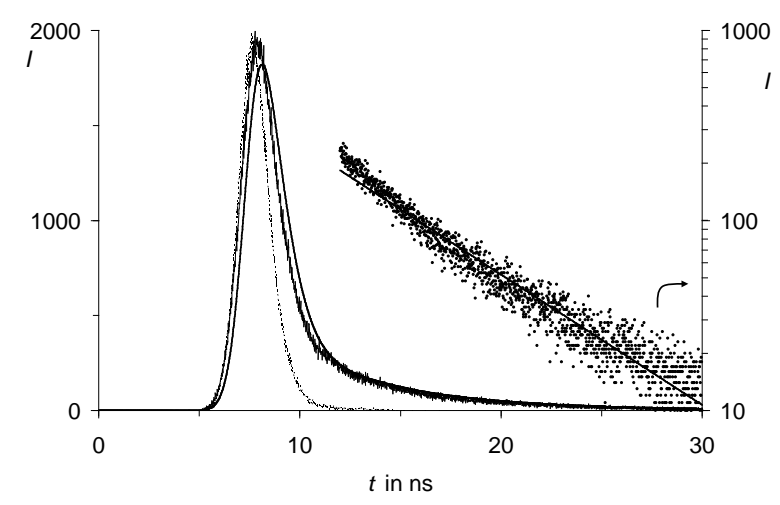

(b)

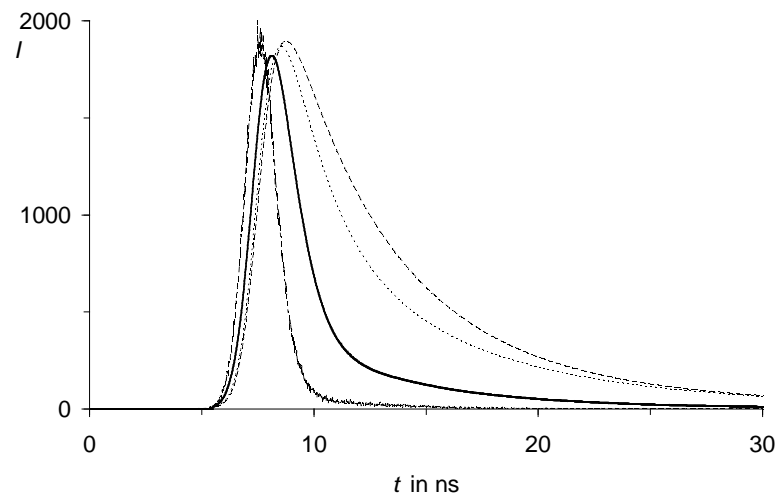

(d)

Figure 2. Fluorescence decay of polymers at $573 \mathrm{~nm}$ in linear (left) and logarithmic scales (right) and the characteristic of the light pulse of excitation at $365 \mathrm{~nm}$ as dotted lines. Mono-exponentially fitted functions of decay as solid lines. (a) Fluorescence decay of Luran $^{\circledR}$; (b) fluorescence decay of Delrin ${ }^{\circledR}$; (c) fluorescence decay of Ultramid ${ }^{\circledR}$; (d) comparison of the fitted functions for Delrin ${ }^{\circledR}$ : Solid line, Ultramid ${ }^{\circledR}$ : Dotted line and Luran ${ }^{\circledR}$ : Dashed line.

entire batch of a polymer for further improvement for the identification of polymers. Moreover, the determination of decay times needs no calibration concerning the fluorescence intensities (such a calibration may by applied with the auto fluorescence of polymers as internal standards), because the exponential decay remains similar independent from the starting intensity and some dead time before acquisition; this may be advantageous, even for very inhomogeneous flakes for recycling concerning size and shape.

We tested the reproducibility of the determined time constant of fluorescence decay and found standard deviation only for the second decimal; see Table 2 for examples. As a consequence, the reproducibility is good enough by far for the unequivocally discrimination between the individual samples; on the other hand, even an 
absolute determination of the time constant is not necessary as long as the complete setup produces sufficiently reproductive values.

\subsection{Time-Resolved Detection}

The first order exponential decay curves need not be completely registered and fitted because there are well established mathematical procedures [12]-[14] for the determination of the time constant by means of the measurements of two points of the decay curve or even more appropriate by two integrated regions, preferment before and behind the half time $\left(t_{1 / 2}\right)$. This is schematically shown with two Gaussian-shaped samplings in Figure 4 where the integrating measurements improve the signal to noise ratio. One up to two ns time for integration time seem to be appropriate concerning a decay time of about $5 \mathrm{~ns}$ for the majority of fluorescent structures. The fluorescence is induced by the periodically pulsed light for excitation where one can expect a sufficiently complete fluorescence decay of $70 \mathrm{~ns}$ for the case of an unfavourable lifetime of $10 \mathrm{~ns}$. As a consequence, an unproblematic frequency of about $15 \mathrm{MHz}$ results for repetition. The two regions of integration may be selected by means of two phase sensitive detectors (PSD) and a phase shift between the two analyzing signals for sampling. These need not be applied for each pulse, but may be distributed, for example, between two consecutive pulses. A further improvement of the signal to noise ratio may be obtained by the accumulation of the signals of detection.

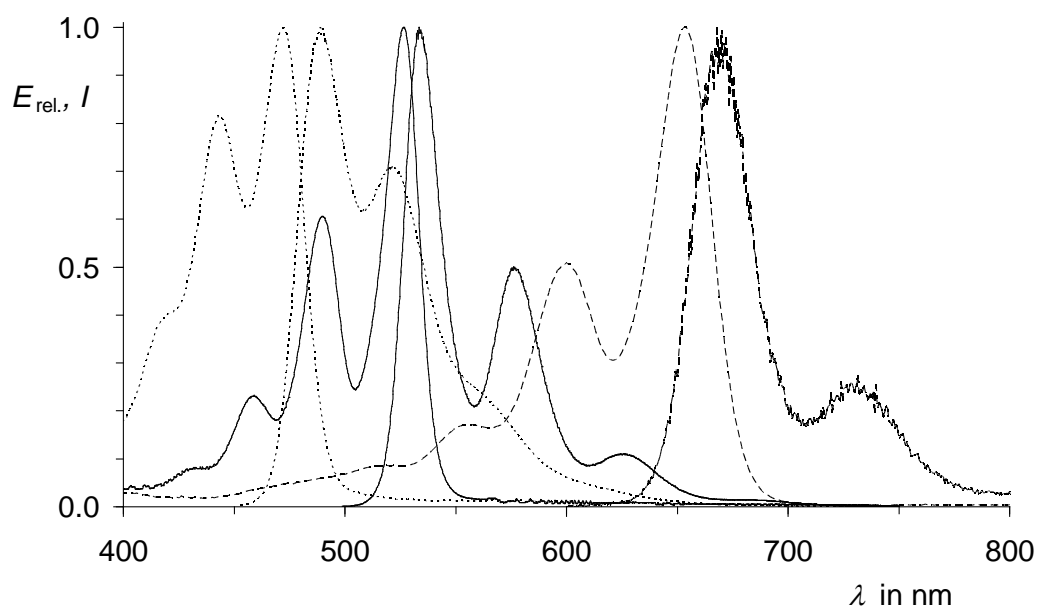

Figure 3. Absorption (left, scale $E$ ) and fluorescence spectra (right, scale $I$ ) of $\mathbf{1}$ (dotted lines), 2 (solid lines) and $\mathbf{3}$ (dashed lines) in chloroform.

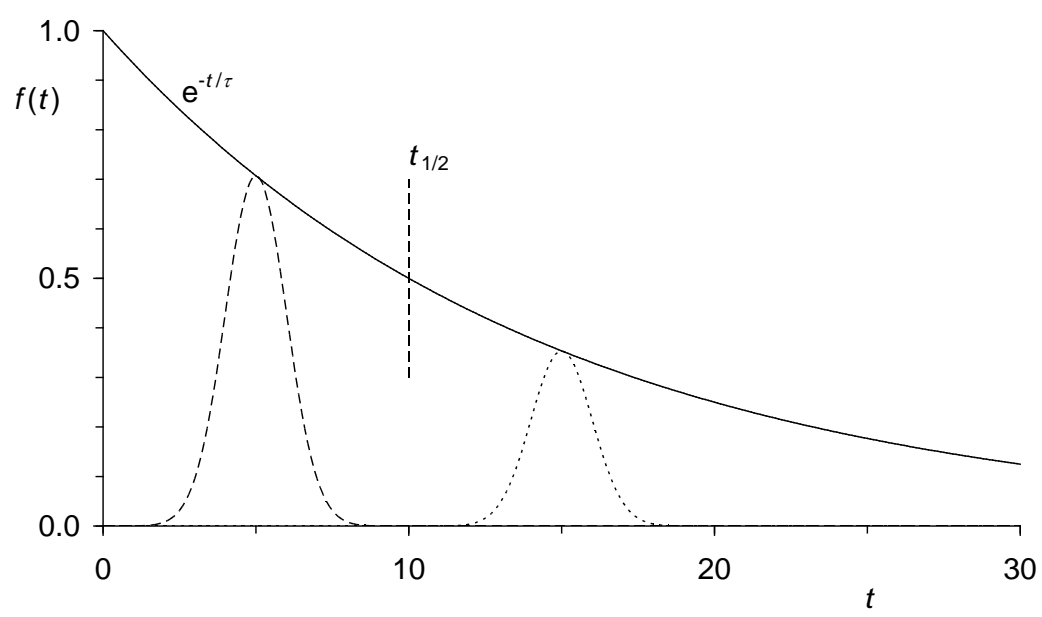

Figure 4. Schematic first order decay (solid line) with a time constant of $\tau=14.4$ ns corresponding to a half life $t_{1 / 2}$ of $10 \mathrm{~ns}$. Gaussian-shaped samplings at $t=5 \mathrm{~ns}$ (dashed curve) and at $t=15$ ns (dotted curve). 
Table 2. Test of reproducibility of the time constant of fluorescence decay including the applied method; measurements with individually prepared and re-oriented samples of labelled granulates.

\begin{tabular}{|c|c|c|c|c|}
\hline Sample & $\tau$ in $\mathrm{ns}^{\mathrm{a})}$ & $\tau \mathrm{m}, \mathrm{s}^{\mathrm{b})}$ & $\lambda \mathrm{ex}^{\mathrm{c})}$ & $\lambda \mathrm{em}^{\mathrm{d})}$ \\
\hline Delrin-PTIE (1) & 3.92 & & 442 & 485 \\
\hline Delrin-PTIE (1) & 3.91 & & 442 & 485 \\
\hline Delrin-PTIE (1) & 3.95 & & 442 & 485 \\
\hline Delrin-PTIE (1) & 3.91 & & 442 & 485 \\
\hline Delrin-PTIE (1) & 3.90 & 3.92, 0.02 & 442 & 485 \\
\hline Delrin-S-13 (2) & 3.78 & & 490 & 573 \\
\hline Delrin-S-13 (2) & 3.77 & & 490 & 573 \\
\hline Delrin-S-13 (2) & 3.79 & & 490 & 573 \\
\hline Delrin-S-13 (2) & 3.79 & & 490 & 573 \\
\hline Delrin-S-13 (2) & 3.73 & & 490 & 573 \\
\hline Delrin-S-13 (2) & 3.74 & $3.77,0.03$ & 490 & 573 \\
\hline Delrin-S-13TBI (3) & 3.35 & & 598 & 667 \\
\hline Delrin-S-13TBI (3) & 3.45 & & 598 & 667 \\
\hline Delrin-S-13TBI (3) & 3.31 & $3.37,0.07$ & 598 & 667 \\
\hline Luran-S-13 (2) & 4.55 & & 490 & 573 \\
\hline Luran-S-13 (2) & 4.56 & & 490 & 573 \\
\hline Luran-S-13 (2) & 4.43 & $4.51,0.07$ & 490 & 573 \\
\hline Ultramid-PTIE (1) & 2.43 & & 442 & 485 \\
\hline Ultramid-PTIE (1) & 2.44 & 2.44 & 442 & 485 \\
\hline
\end{tabular}

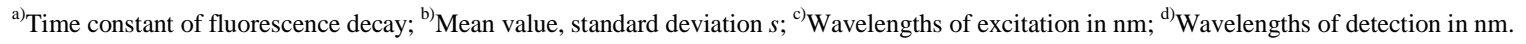

One can roughly calculate the upper limit of the detection for sorting with industrial flakes for recycling of dimension of max. $10 \mathrm{~mm}$. Minimal $20 \mathrm{~mm}$ space between the individual flakes seem to be realistic and a transport of maximal $500 \mathrm{~m} / \mathrm{s}$ where 200 pulses for excitation at $15 \mathrm{MHz}$ of repetition should be obtainable for a single flake; this should be more than sufficient for a good signal to noise ratio for an unequivocal sorting. An average mass of about $25 \mathrm{mg}$ was found for standard industrial recycling flakes resulting in a sorting capacity of 1.5 tons of material per hour. This has to be taken as an upper technological limit for a permanent sorting of polymers covered by the described method. The bottleneck for such capacities seems to be more the mechanics than the methodology of detection. Both electronics and mechanics become much more simple for lower demand.

\section{Conclusion}

The unequivocal identification of technical polymers by means of their time constants of auto fluorescence decay is a promising method for their sorting for recycling. Time constants can be economically determined by phase-shifted integration of the fluorescence response of pulsed optical excitation. The auto fluorescence of polymers can be applied for the identification of the basic material where a doping with fluorescent dyes allows the further fine-classification of special batches. A binary coding of the doping with $n$ fluorescent dyes results in $2^{n}-1$ possibilities for the labelling of batches.

\section{Acknowledgements}

This work was supported by The BMBF, CIPSM cluster in Munich, and the Fonds der Chemischen Industrie. We thank Dr. Moritz Ehrl for technical assistance.

\section{References}

[1] Nemeth, E., Schubert, G., Albrecht, V. and Simon, F. (2005) Procedure for Sorted, Electrostatic Separation of Mixed Plastics Wastes. Aufbereitungs-Technik, 46, 35-46. 
[2] Nemeth, E., Simon, F., Albrecht, V. and Schubert, G. (2004) Procedure for Sorted, Electrostatic Separation of Mixed Plastics Wastes. Ger. Patent No. 102004024754 B3; Chemical Abstracts, 144, 392348.

[3] Gohs, U., Albrecht, V., Husemann, K., Reinsch, E., Schuenemann, R. and Simon, F. (2009) Procedure for the Electrostatic Separation of Mixed Plastics Waste. Ger. Offen. No. DE 102007055765 A1; Chemical Abstracts, 151, 57663.

[4] Corbet, E.C. Frey, J.G., Groce, R.I. and Hendra, P.J. (1994) An Investigation into the Applicability of Luminescent Tagging to Polymer Recovery. Plastics, Rubber and Composite Processing and Application, 21, 5-11.

[5] Rafi Ahmad, S. (2000) Marking of Products with Fluorescence Tracers in Binary Combinations for Automatic Identification and Sorting. Assembly Automatation, 20, 58-65. http://dx.doi.org/10.1108/01445150010311617

[6] Alam, M.K., Stanton, S.L. and Hebner, G.A. (1994) Near Infrard Spectroscopy and Neural Network for Resin Identification. Spectroscopy, 9, 31-39.

[7] Scott, D.M. (1995) A Two-Colour near Infra-Red Sensor for Sorting Recycled Plastic Waste. Measurement Science and Technology, 6, 156-159. http://dx.doi.org/10.1088/0957-0233/6/2/004

[8] General Electric Company; Hubbard, S., Potyrailo, R., Schottland, P. and Thomas, V. (2006) Tagging Materials for Polymers, Methods, and Articles Made Thereby. US Patent No. 2005/0095715 (Oct. 31, 2003); Chem. Abstr. 2005, 142, 412287.

[9] General Electric (inv. Hubbard, S.F., Potyrailo, R.A., Schottland, P. and Thomas, V.) (2003) Tagging Materials for Polymers, Methods, and Articles Made Thereby. PCT Int. Appl. (2003), WO 2003006965 A1 20030123; Chemical Abstracts, 138, 107667.

[10] Langhals, H., Schmid, T., Herman, M., Zwiener, M. and Hofer, A. (2013) Binary Fluorescence Labeling for the Recovery of Polymeric Materials for Recycling. International Journal of Environmental Engineering, 7, 124-132.

[11] Langhals, H., Schmid, T., Herman, M., Zwiener, M. and Hofer, A. (2012) Marking of Polymer Materials with Fluorescence Dyes for Their Clear Automatic Sorting. Ger. Offen. No. DE 102012012772.3; Chemical Abstracts, 160, 63983.

[12] Ballew, R.M. and Demas, J.N. (1989) An Error Analysis of the Rapid Lifetime Determination Method for the Evaluation of Single Exponential Decays. Analytical Chemistry, 61, 30-33. http://dx.doi.org/10.1021/ac00176a007

[13] Woods, R.J., Scypinski, S., Cline Love, L.J. and Ashworth, H.A. (1984) Transient Digitizer for the Determination of Microsecond Luminescence Lifetimes. Analytical Chemistry, 56, 1395-1400. http://dx.doi.org/10.1021/ac00272a043

[14] Meier, R.J., Fischer, L.H., Wolfbeis, O.S. and Schäferling, M. (2013) Referenced Luminescent Sensing and Imaging with Digital Color Cameras: A Comparative Study. Sensors and Actuators B, 177, 500-506. http://dx.doi.org/10.1016/j.snb.2012.11.041

[15] Alibert-Fouet, S., Seguy, I., Bobo, J.-F., Destruel, P. and Bock, H. (2007) Liquid-Crystalline and Electron-Deficient Coronene Oligocarboxylic Esters and Imides by Twofold Benzogenic Diels-Alder Reactions on Perylenes. European Journal of Chemistry, 13, 1746-1753. http://dx.doi.org/10.1002/chem.200601416

[16] Demmig, S. and Langhals, H. (1988) Readily Soluble Lightfast Perylene Dyes. Chemische Berichte, 121, 225-230. http://dx.doi.org/10.1002/cber.19881210205

[17] Langhals, H. and Poxleitner, S. (2008) Core-Extended Terrylene Bisimides-Novel, Strongly Red Fluorescent Broadband Absorbers. European Journal of Organic Chemistry, 2008, 797-800. http://dx.doi.org/10.1002/ejoc.200701058

[18] Langhals, H., Walter, A., Rosenbaum, E. and Johansson, L.B.-Å. (2011) A Versatile Standard for Bathochromic Fluorescence Based on Intramolecular FRET. Physical Chemistry Chemical Physics, 13, 11055-11059.

http://dx.doi.org/10.1039/c1cp20467j 
Scientific Research Publishing (SCIRP) is one of the largest Open Access journal publishers. It is currently publishing more than 200 open access, online, peer-reviewed journals covering a wide range of academic disciplines. SCIRP serves the worldwide academic communities and contributes to the progress and application of science with its publication.

Other selected journals from SCIRP are listed as below. Submit your manuscript to us via either submit@scirp.org or Online Submission Portal.
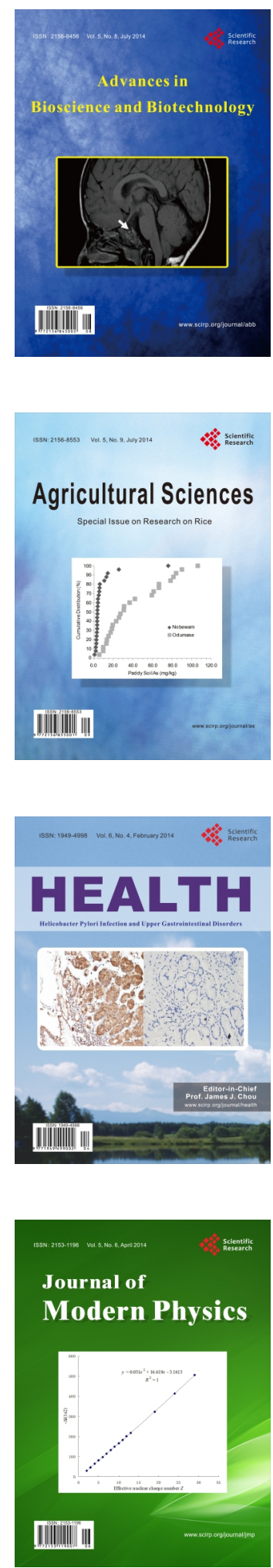
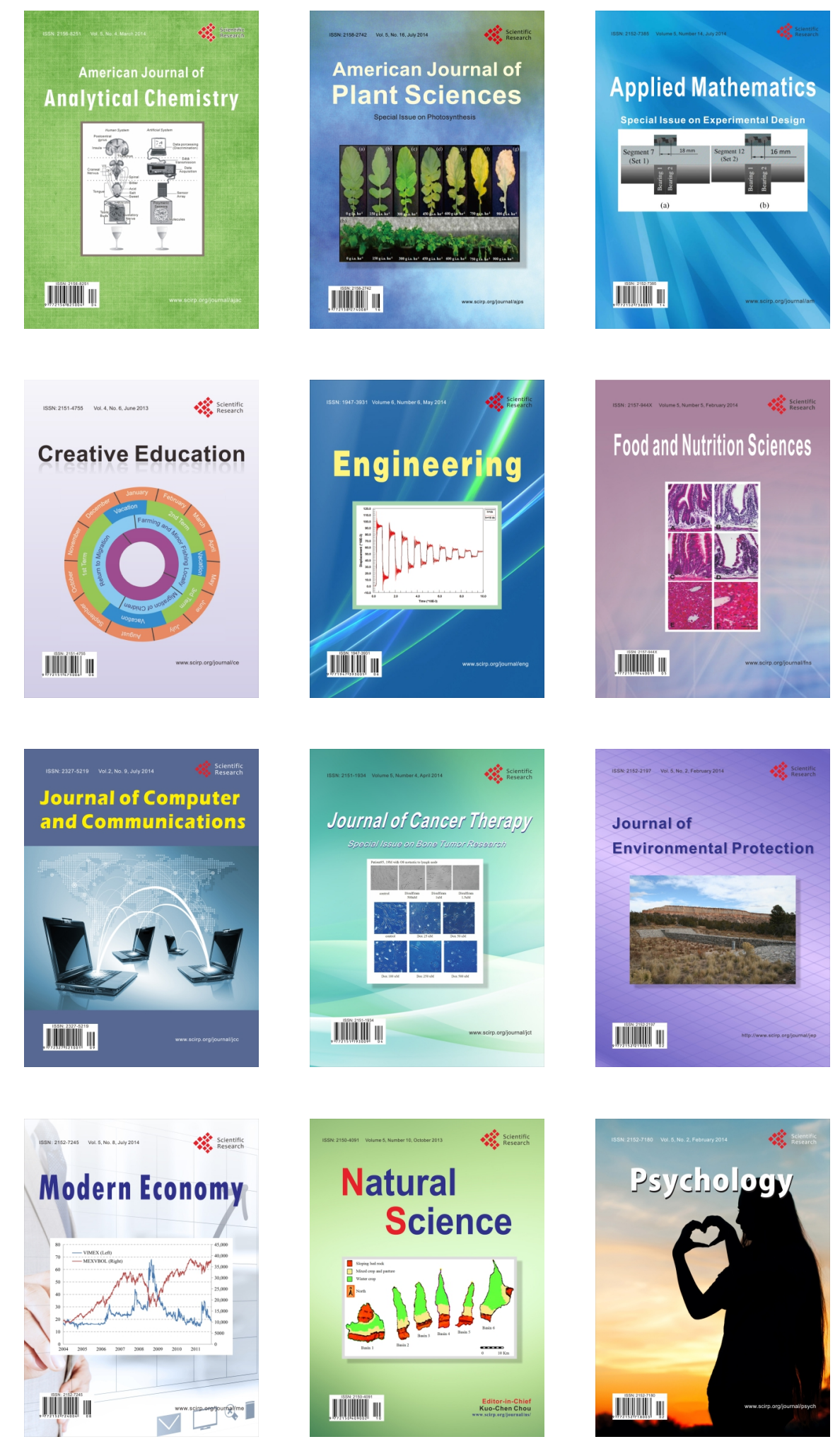